7 Culver AJ. The rationing debate: maximising the health of the whole community. BMJ 1997:314:667-9.

8 National Institute for Clinical Excellence. Anakinra for rheumatoid arthritis. London: NICE, 2003. (Technology appraisal No 72.) www.nice.org.uk/ page.aspx?o $=94670$ (accessed 25 Jun 2004)

9 National Institute for Clinical Excellence. Beta interferon and glatiramer acetate for the treatment of multiple sclerosis. London: NICE, 2002. (Technology appraisal No 32.) www.nice.org.uk/page.aspx?o $=27588$ (accessed 25 Jun 2004).

10 National Institute for Clinical Excellence. Guidance on the use of imatinib for chronic myeloid leukaemia. London: NICE, 2002. (Technology appraisal No 50.) www.nice.org.uk/page.aspx?o $=37604$ (accessed 25 Jun 2004).

11 NICE Citizens Council. Report of the first meeting:Determining clinical need. London: NICE, 2003. www.nice.org.uk/pdf/FINALNICEFirstMeeting FINAL Report pdf (accessed 25 Jun 2004).

12 NICE Citizens Council. Report on age. London: NICE, 2003. www.nice.org.uk/pdf/Citizenscouncil_report_age.pdf (accessed 25 Jun 2004).
13 Brazier JN, Jones N, Kind P. Testing the validity of the Euroqol and comparing it with the SF-36 health survey questionnaire. Oual Life Res 1993;2:169-80.

14 Anderson RT, Aaronson NK, Bullinger M, McBee WL. A review of the progress towards developing health-related quality-of-life instruments for international clinical studies and outcomes research. Pharmacoeconomics 1996;10:336-55

15 Brooks R. EuroQol: the current state of play. Health Policy 1996;37:53-72. 16 Roset M, Badia X, Mayo NE. Sample size calculations in studies using the EuroQol 5D. Qual Life Res 1999;8:539-49.

17 Kind P, Hardman G, Macran S. UK population norms for EQ-5D. York: Centre for Health Economics, 1999 (Discussion paper No 172).

18 Culyer AJ, Wagstaff A. Equity and equality in health and health care. $J$ Health Econ 1993;12:431-57.

19 Culver AJ. Economics and ethics in healthcare. J Med Ethics 2001;27:217-22. 20 Culyer AJ. Equity-some theory and its policy implications. J Med Ethics 2001;27:275-83

21 Culyer AJ. Need: the idea won't do-but we still need it. Soc Sci Med 1995; $40: 727-30$

\title{
Challenges for the National Institute for Clinical Excellence
}

Alan Maynard, Karen Bloor, Nick Freemantle

So far NICE has focused on evaluating new technologies rather than existing ones. But this approach is creating inflationary pressure that the NHS cannot afford

Even with recent large increases in NHS expenditure, acute funding difficulties continue to emerge. It is essential that a national mechanism to prioritise new and existing technologies is available to inform decision making. The National Institute for Clinical Excellence (NICE) was created to meet this need. ${ }^{1}$ However, despite Rawlins and Culyer's essay on consultation and equity, ${ }^{2} \mathrm{NICE}$ has yet to mature into the efficient prioritisation mechanism that is required to ensure the best use of NHS resources.

\section{Rationing}

Rawlins has stated that there is "no role for NICE in the rationing of treatments to NHS patients."” These weasel words belie the inevitability of healthcare rationing, which is ubiquitous in all healthcare systems. Rationing involves depriving patients of care from which they may benefit and which they wish to have; this is inescapably the business of NICE. Indeed, rationing is the inevitable corollary of prioritisation, and NICE must fully inform rationing in the NHS.

The issue is not whether but how to ration. The criteria determining access to care depend on the health

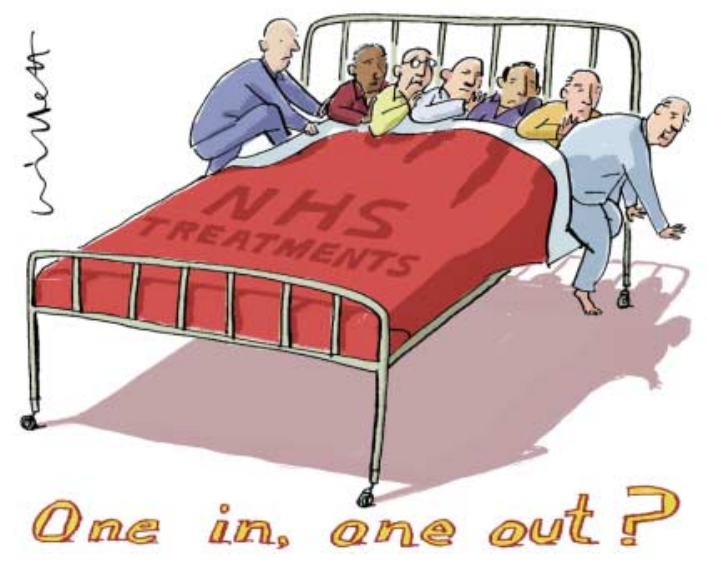

goals society is seeking to achieve. Are we solely interested in efficient use of resources-maximising health from a given budget? Or does society seek efficiency and equity and, if so, is it prepared to sacrifice some efficiency to achieve equity goals? The central nature of NICE as a prioritisation (and hence rationing) body means that four fundamental challenges emerge. These challenges need to be managed carefully and robustly if NICE is to prosper, as we discuss below.

\section{Restricting access to NHS funding}

Currently the role of NICE is too peripheral to the NHS. For instance, the government should make it impossible for the NHS to adopt expensive new technologies until they are approved by NICE. The additional benefits of most technologies are small-for example, taxanes may add only a few more months to life and have adverse side effects for cancer patients. The function of NICE is to reach a consensus about clinical and economic evidence. This does not imply that only cost effective treatments should be funded but that decisions to fund interventions under the NHS should be taken after careful consideration of the best possible information. Such consideration should be done before, not after, the introduction of new technologies.

\section{Equity and efficiency trade-offs}

Society is clearly not concerned only with efficiency and using NHS budgets to maximise improvements in population health. The NHS, in its usual fragmented and implicit way, illustrates different value systems-for example, by investing "inefficiently" in low birthweight babies because our society values highly the lives of the newly born. In some cases NICE has also operated a rule of rescue approach to its recommendations rather than one based solely on effectiveness or cost effectiveness. $^{5}$
Department of Health Sciences, University of York, York YO10 5DD

Alan Maynard professor Karen Bloor senior research fellow

Department of Primary Care and General Practice,

University of Birmingham, Birmingham B15 2TT

Nick Freemantle professor

Correspondence to: A Maynard akm3@york.ac.uk

BMJ 2004;329:227-9 
If the NHS seeks to achieve greater fairness-for example, by making quality adjusted life expectancy more equally distributed through the population-it follows that NICE must not focus on clinical or cost effectiveness alone. Its work has to recognise the equity dimension of healthcare rationing and elicit appropriate trade-offs between efficiency and equity. This could be achieved, for example, by implementing a fair innings approach, reflecting the belief that everybody is entitled to a "normal" span of health. ${ }^{4}$ Under this approach, resources would be allocated in order to achieve equitable distributions of health rather than to simply maximise health benefits regardless of who benefits. ${ }^{4}$

The NHS and other public healthcare systems were created to improve equity by equalising access to care in the hope of reducing inequalities in health. With NICE providing national guidance on the use of healthcare interventions in the English and Welsh NHS, it is inappropriate that it continues to avoid its responsibilities in terms of achieving equity.

\section{Selecting technologies for approval}

Problems also exist with the political process through which topics are chosen for NICE. Although some effort has been made to broaden the sources of suggestions for appraisals, there continues to be overemphasis on new technologies and relatively little attention paid to old technologies that may be redundant. Such technologies could potentially create resource savings to fund the inflationary pressures of NICE.

Careful discussion is needed about how to improve the selection processes further. It might be useful to experiment, by canvassing a wider group of NHS decision makers, with some form of reward for nominating appraisals that could save the NHS appreciable resources. NICE has developed patient forums to inform its work but could take steps to increase the involvement of NHS staff (who bear the burden of translating NICE guidance into practice) in selecting appraisal topics. Such group decisions should be informed by using activity and prescribing data to identify the procedures for which expenditure is greatest and estimate the relative financial burdens of common procedures.

This information would induce NHS decision makers to focus more on withdrawing ineffective or inefficient marginal therapies. Perhaps decision makers who initiate such appraisals should be able to retain their local savings? At present, the selection process remains largely political and only indirectly influenced by those who face difficult decisions in service delivery.

\section{Mechanisms to constrain NICE induced inflation}

As Rawlins and Culyer describe, ${ }^{2}$ NICE does not have a set threshold at which it is prepared to approve treatments. This has led to the approval of some therapies with small benefits-for instance, in cancer treatment. ${ }^{6}$ NICE approvals cause NHS provider organisations

\section{Summary points}

Rationing health care is inevitable, and NICE should inform NHS decision making

Adoption of new technologies by NHS clinicians should be informed by costs as well as effectiveness

The NHS needs better information from NICE on the equity implications of new and existing technologies

NICE appraisal should focus not only on service enhancement but also on withdrawal of existing ineffective or inefficient therapies

Giving NICE a real budget to fund its recommendations would encourage it to examine the effect of its decisions on the whole NHS

considerable difficulty because of the other cost pressures they face. These include inflationary pay settlements, the working time directive, and pressure to achieve access and national service framework targets. Although practitioners who benefit from NICE induced service development may be enthusiastic, the opportunity costs for other service providers are considerable.

Current consideration of other aspects of the pharmaceutical market may further increase NHS expenditure. These include the proposed reform of the Pharmaceutical Price Regulation Scheme, with "free" pricing of products as one policy option, ${ }^{7}$ and recent pressure from the commissioner of the US Food and Drug Administration for higher prices in Europe, so that a larger proportion of research and development costs is borne there. ${ }^{8}$

Against this background, and given the NICE threshold for approval is essentially arbitrary, ways have to be found to economise the use of drugs and other technologies. This issue could be approached in several ways:

- Acquire the preferences of key decision makers-for instance NHS chief executives (motivated by the solvency of their organisations as well as patient health) and use them to determine the threshold. This could lower threshold, perhaps to £12 000-15 000/ quality adjusted life year $(\$ 22000-28000, € 18000$ $23000)$ and result in NICE rejecting many more technologies for NHS use.

- Give NICE an annual notional budget to fund its recommendations. For example, NICE could be given $£ 500 \mathrm{~m}$ a year and would have to cost carefully its proposals and stay within that notional budget or recommend services suitable to withdraw to fund the new services

- Give NICE an annual, top sliced, real budget and require it to fund all its advice within that expenditure envelope with allocations to trusts to fund its recommendations.

The most efficient of these three options is likely to be the third. This would force NICE to 
determine the value of the additional therapies at the margin, examine the effect of their decisions on the whole NHS, and also provide incentives to balance cost enhancing against cost reducing recommendations.

The pharmaceutical industry is unlikely to react positively to these proposals, as they would make rationing tighter and potentially shrink its UK market. Such a reversal of NICE's current propensity to be the marketing arm for companies would have political consequences and requires careful management.

\section{Conclusions}

It is not sufficient for Rawlins and Culyer ${ }^{2}$ to claim that the resource implications from NICE decisions are the responsibility of government. A new approach has to be found to manage the use of drugs and other technologies within the NHS. We believe NICE should be given a real, annual, top sliced budget and required to fund all its advice within that expenditure envelope. This will have the advantage of forcing NICE to examine the cost effectiveness of existing treatments as well as new ones.

The success of commercial, provider, and regulatory interests in focusing NICE's work on new, expensive technologies has been self serving and inflationary. This inflation should be controlled through manipulation of the NICE threshold for approval. The NHS cannot afford NICE generosity, even with increased NHS funding, because of the resource demands of other access and national service framework targets, many of which have yet to be evaluated by NICE.

Greater success in rationing will bring greater political and media challenges. These should be anticipated and managed carefully. This will be especially important as over the next few years the current substantial growth in NHS expenditure is likely to fade, and NICE will have to make hard choices in a much more difficult economic climate.

An earlier draft of this paper has been improved considerably with advice and comments from Diane Dawson, Mike Drummond, Mark Sculpher, and Alan Williams and was presented at NICE's annual conference by Alan Maynard in December 2003. We thank them for their help and apologise if we have misinterpreted any of it. We also thank Anne Burton and Sandi Newby for administrative help.

Contributors and sources: The authors have longstanding research interests in health economics and health policy. This article arose from discussions following the NICE annual conference, and from consideration of these issues since before the inception of NICE. AM wrote the first draft of this article after discussions with the other authors and acts as guarantor. All authors contributed to later drafts.

Competing interests: AM is chair of York Hospitals NHS Trust and $\mathrm{KB}$ is non-executive director of Selby and York Primary Care Trust.

1 Bloor K, Maynard A. Regulating the pharmaceutical industry. BMJ 1997;315:200-1

2 Rawlins MD, Culyer AJ. National Institute for Clinical Excellence and its value judgments. BMJ 2004;328:224-7.

3 Association of the British Pharmaceutical Industry. The expert patient. London: ABPI, 1999. www.abpi.org.uk/publications/publication_details/ expert patient/power_point doc_NICE.asp (accessed 14 October 2003). 4 Williams A. Intergenerational equity: an exploration of the fair innings. Health Economics 1997;6:117-32.

Freemantle N, Bloor K, Eastaugh J. A fair innings for NICE? Pharmacoeconomics 2002;20:389-91.

6 Garatini S, Bertele V. Eefficacy, safety and the cost of new anticancer drugs. BMJ 2002;325:269-71.

- drugs. BMj $2002: 325: 269-71$.

Department of Health. Pharmaceutical price regulation scheme: discussion document. London: DoH, 2003. www.dh.gov.uk/Consultations/ ClosedConsultations/ClosedConsultationsArticle/fs/en? (accessed 28 June 2004)

8 Hopkins J. FDA chief wants other rich countries to share drug development costs. BMJ 2003;327:830.

(Accepted 23 June 2004)

\section{A memorable patient}

\section{How life events change patients' perspectives of their conditions}

In September 1939 the second world war had just begun as Germany invaded Poland, and 12 year old Agnes was evacuated from Liverpool to a family in Northwich, Cheshire, for safety from bombing. Within a few months her dormant atopic eczema had flared, and she was treated at a local clinic. By March 1940, her mother was missing her and decided, as most Liverpool mothers did, to bring her child back home to the city as she preferred to have all the family together if the worse should happen.

Around this time the government implemented a Children's Overseas Reception Board, a plan designed to keep children safe from German attack by placing them in Commonwealth countries (New Zealand, Australia, Canada) or the United States with relatives or willing host families for the duration of the war. Agnes was placed on the list as her father had a sister living in New York at the time.

The eczema flared again, starting on her neck, and a few days later it extended. Her excoriated eczematised skin was complicated by extensive herpes simplex over the face. It was so severe that she was only able to drink through a straw. Regular medical check ups were mandatory for would-be evacuee children, as they had to be fit and ready to leave at a moment's notice. Agnes attended the Sugnall Street Clinic behind the
Philharmonic Hall. She was prescribed sulphur ointment, which began to heal her infected skin.

A ship then arrived in the port of Liverpool to take the children away from the very real dangers of war. However, Agnes's mother received a letter stating that her daughter would not be included because her rash had not cleared and the risk of spreading infection to others aboard was still present. This was a major disappointment, as the family was having to shelter under the Anglican Cathedral from the German bombs. Agnes's mother, however, consoled her by saying "Man proposes, but God disposes."

She was proved right, as the ship on which Agnes had been due to sail was the ill fated City of Benares. This ship was torpedoed 600 miles and five days out from Liverpool by the German U-boat 48 on 17 September 1940 at $1030 \mathrm{pm}$ with the loss of 294 lives, including 73 children, 11 of whom were from Liverpool. This tragedy ended the Children's Overseas Reception Board.

Agnes never complains when she has a flare of her eczema as she realises it ultimately saved her life.

Julian Verbov professor of dermatology, Royal Liverpool Children's Hospital, Liverpool 